Supporting Information

\title{
Anisotropic, Flexible Wood Hydrogel and Wrinkled, Electrodeposited Film Electrode for Highly Sensitive, Wide-range Pressure Sensing
}

Kang-Chen Nie, Zhao-Song Wang, Rui-Xin Tang, Li Zheng, Cai-Cai Li, Xiao-Ping Shen*, and Qing-Feng Sun*

School of Engineering, Zhejiang A\&F University,Hangzhou 311300, People's Republic of China

*Corresponding author’s Email: xpshen@zafu.edu.cn (X.P. Shen); qfsun@zafu.edu.cn (Q.F. Sun). 

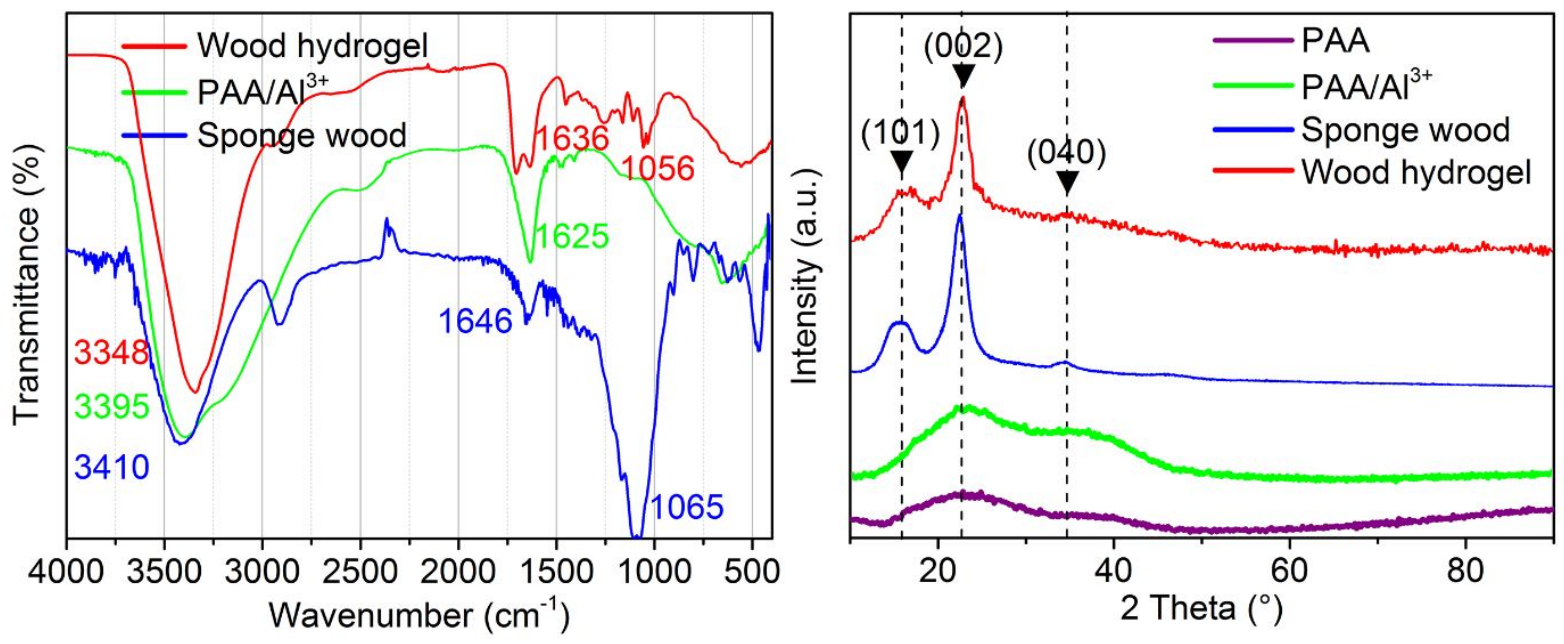

Figure. S1 (a) FT-IR spectra of wood sponge, PAA/Al ${ }^{3+}$ and wood hydrogel. (b) XRD patterns of PAA, PAA/Al ${ }^{3+}$, wood sponge and wood hydrogel.
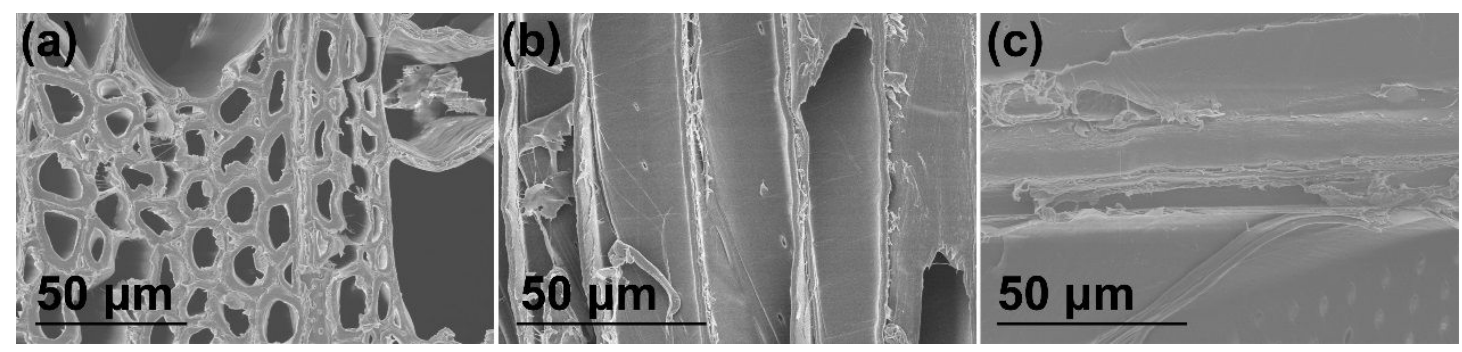

Figure. S2 The SEM images of the (a) cross-section, (b) radial section and (c) tangential section of wood. 


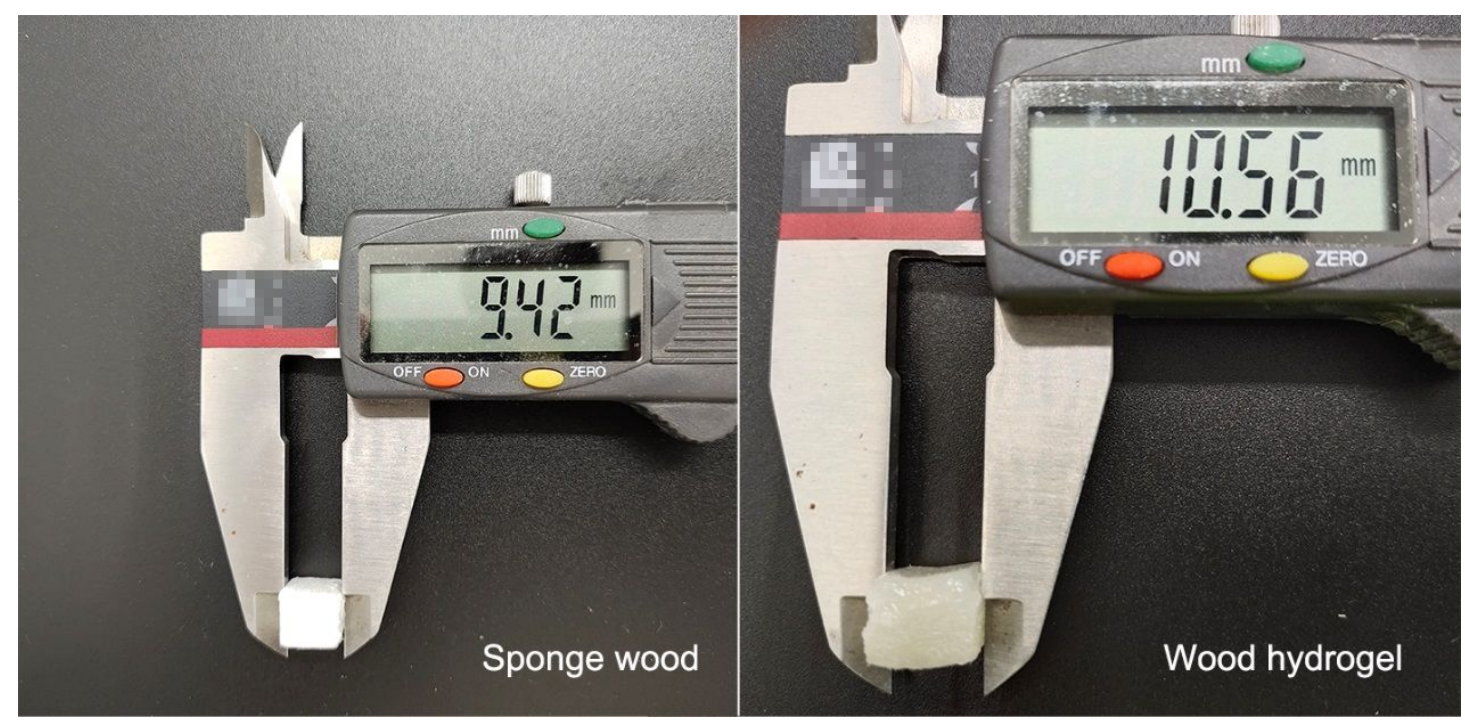

Figure. S3 Macro-size change photos of wood sponge and wood hydrogel after PAA polymerization.

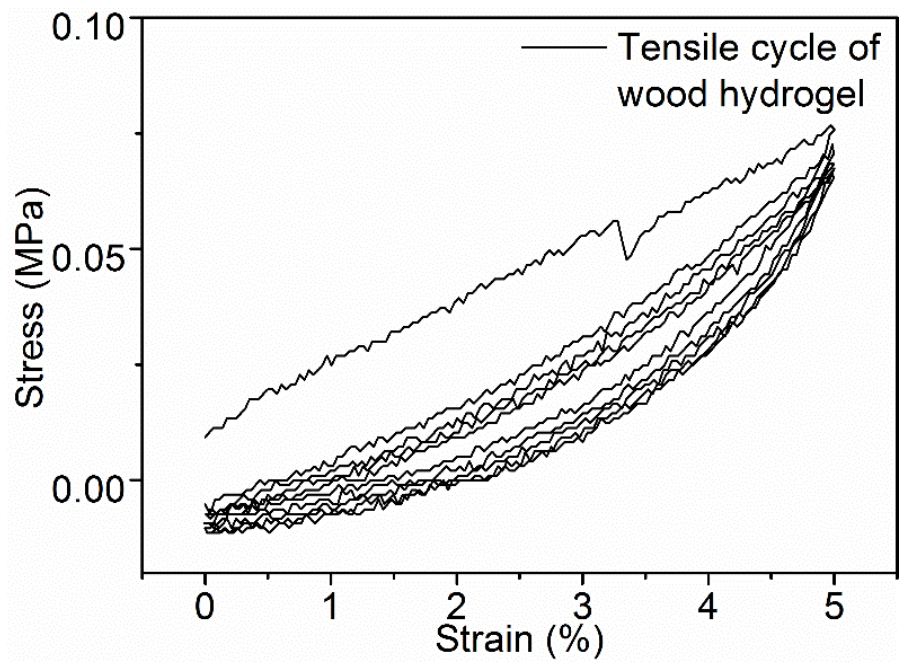

Figure. S4 The cyclic tensile stress-strain performance of wood hydrogel. 


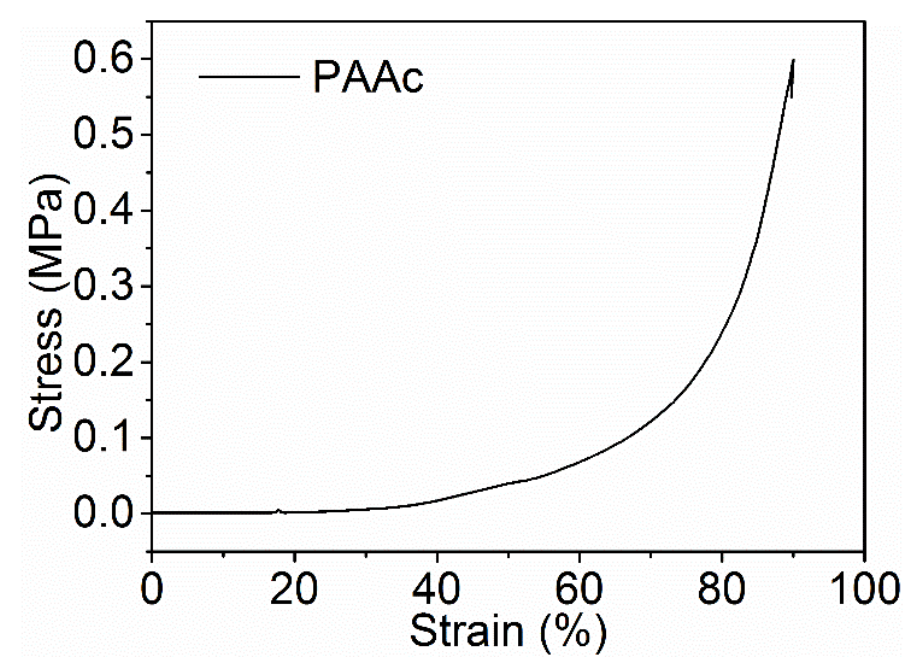

Figure. S5 The compressive strength of the pure PAA hydrogel.

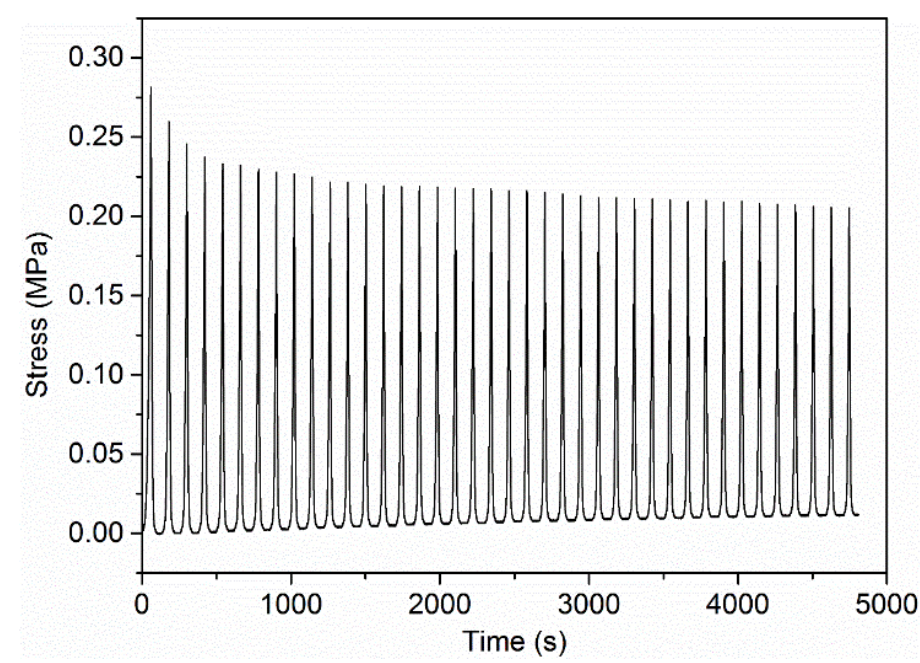

Figure.S6 The loading-unloading compression cycles (40 times) of the tangential wood hydrogel. 
Figure.S7 A 3D microscope picture of the cross-section of wood sponge. The early wood was easier to crack.

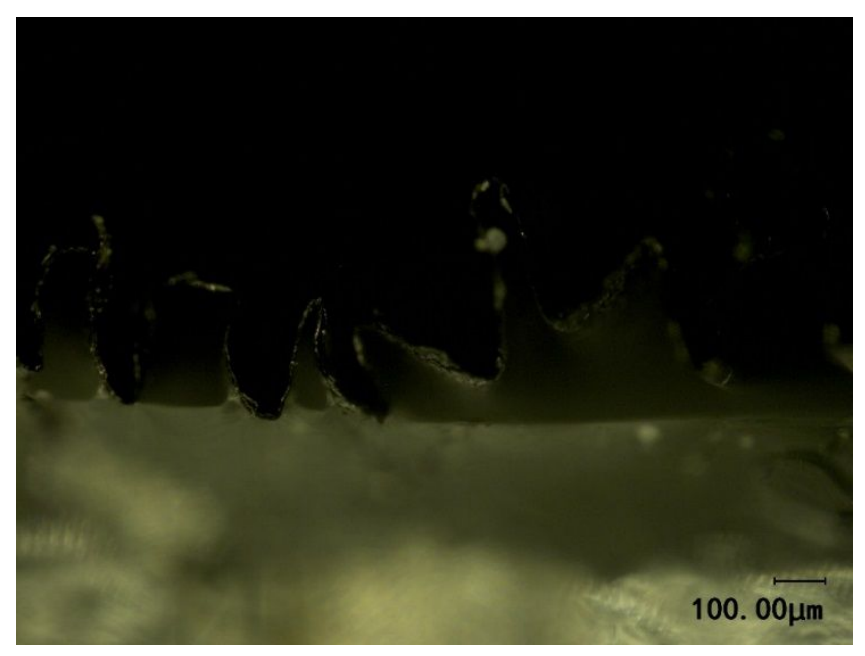

Figure.S8 A 3D microscope picture of the rGO film. 


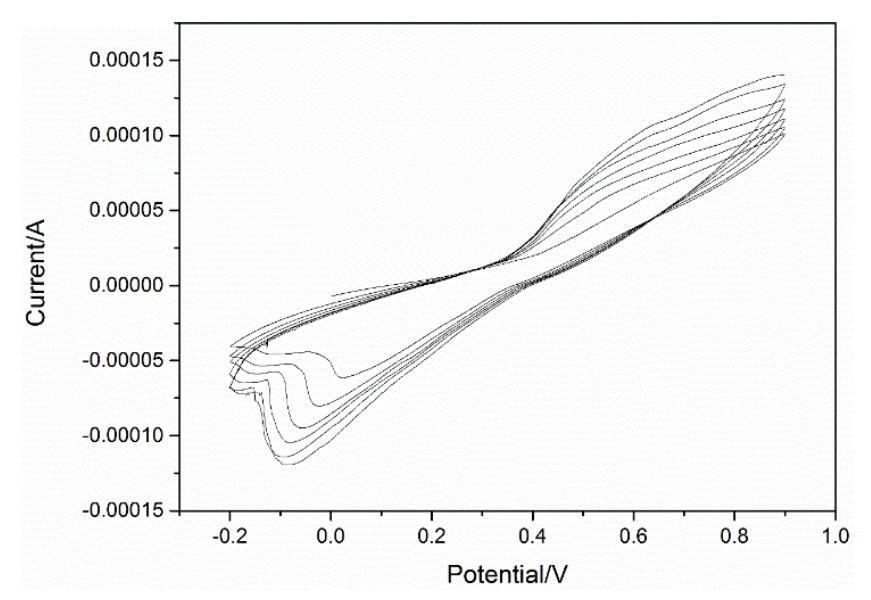

Figure.S9 Cyclic voltammetry curve of the rGO film during the elctrodeposition of PANI.

Table S1 Results of the thickness and conductivity of rGO and rGO-PANI measured by FourPoint Probes.

\begin{tabular}{llllll}
\hline Samples & $\begin{array}{l}\text { Thickness } \\
(\mathrm{mm})\end{array}$ & $\begin{array}{l}\text { Weight } \\
(\mathrm{g})\end{array}$ & $\begin{array}{l}\text { Resistance } \\
(\Omega)\end{array}$ & $\begin{array}{l}\text { Resistivity } \\
(\Omega \cdot \mathrm{mm})\end{array}$ & $\begin{array}{l}\text { Conductivity } \\
(\mathrm{S} / \mathrm{mm})\end{array}$ \\
\hline rGO & 0.01 & 0.0104 & 13 & 0.130 & 7.692 \\
rGO-PANI & 0.01 & 0.0114 & 11.7 & 0.117 & 8.547 \\
\hline
\end{tabular}



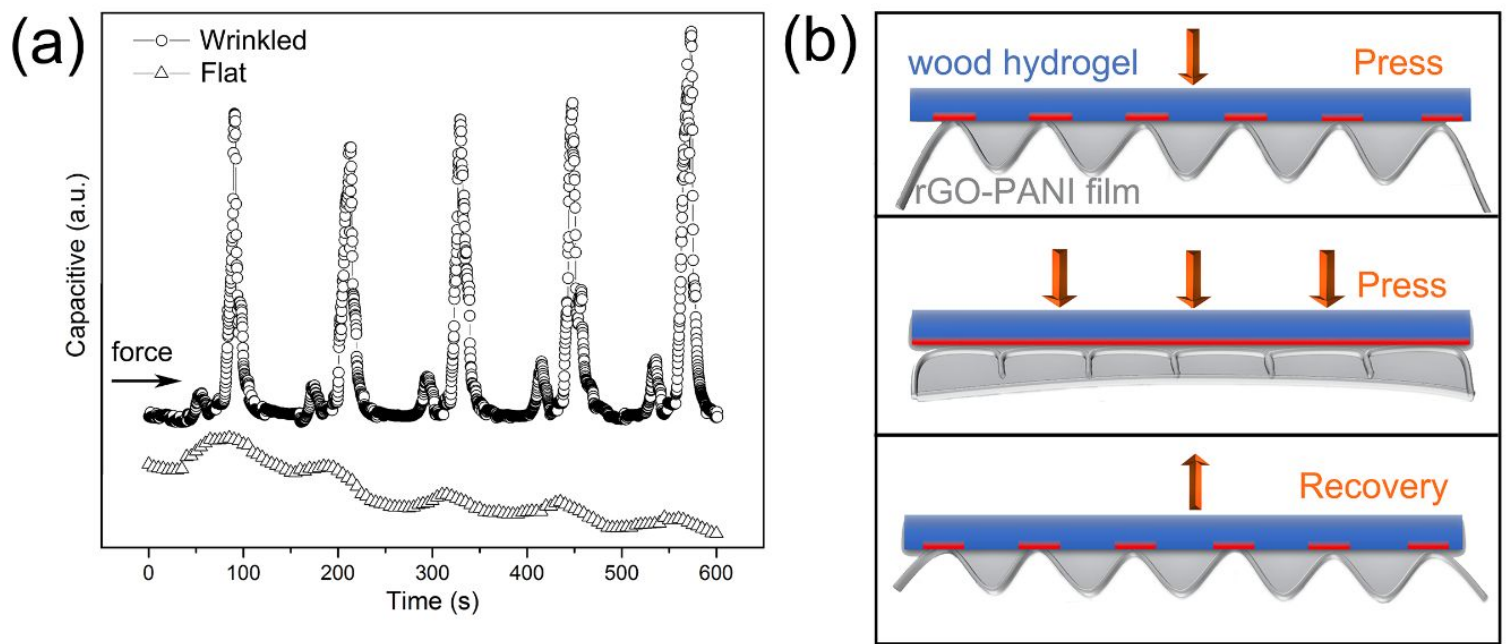

Figure. S10 (a) Comparison of the sensing capacity of CPSsassembled with a wrinkled rGO and without a wrinkled rGO. (b) The corresponding mechanism diagram of the wrinkled rGOPANI electrode under a stress.

Table S2 Comparison of sensitivity and stress ranges.

\begin{tabular}{|c|c|c|c|c|}
\hline Reference & Type of sensor & Materials & Range ability & Sensitivity \\
\hline 22 & Capacitive & AgNWs@PDMS & $15 \mathrm{KPa}$ & $\begin{array}{l}1.194 \mathrm{KPa}^{-1}(<2 \\
\mathrm{KPa}), 0.077 \\
\mathrm{KPa}^{-1}\end{array}$ \\
\hline 40 & Capacitive & Knit/sugar granules & $1 \mathrm{MPa}$ & $12.1 \mathrm{MPa}^{-1}$ \\
\hline 41 & Capacitive & AgNWs/Ecoflex & $1.2 \mathrm{MPa}$ & $\begin{array}{l}1.6 \mathrm{MPa}^{-1}(<500 \\
\mathrm{KPa}), 0.57 \mathrm{MPa} \\
1\end{array}$ \\
\hline 42 & Piezoresistive & $\begin{array}{l}\text { cellulose/graphene } \\
\text { composites }\end{array}$ & $48 \mathrm{MPa}$ & $0.4 \mathrm{MPa}^{-1}$ \\
\hline 43 & Piezoresistive & PAAm/PVA hydrogel & $7 \mathrm{kPa}$ & $\begin{array}{l}50 \mathrm{MPa}^{-} \\
{ }^{1}(<3.27 \mathrm{kPa}) \\
20 \mathrm{MPa}^{-1}\end{array}$ \\
\hline
\end{tabular}


Our work Capacitive $\quad \mathrm{rGO} /$ wood hydrogel $\quad 1.6 \mathrm{MPa} \quad 41.8 \mathrm{MPa}^{-}$

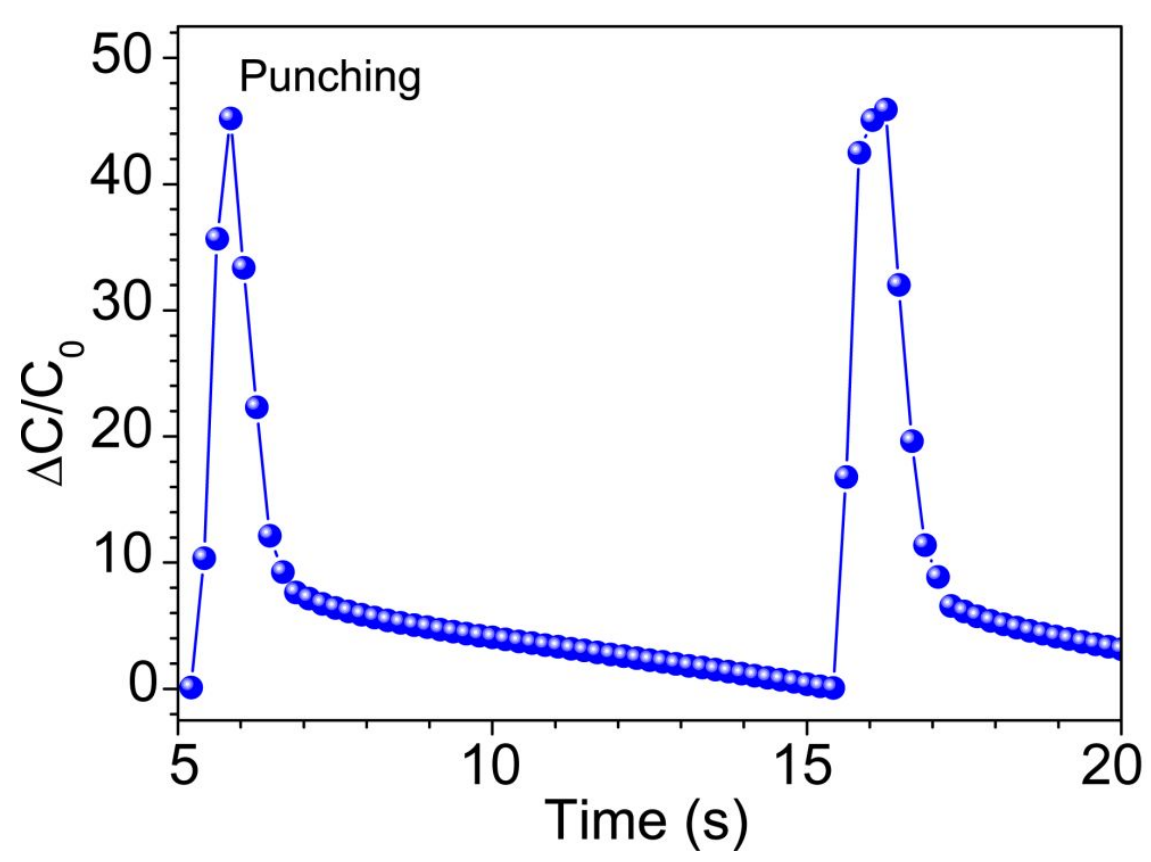

Figure.S11 Responsive and recovery time during punching sensing. 

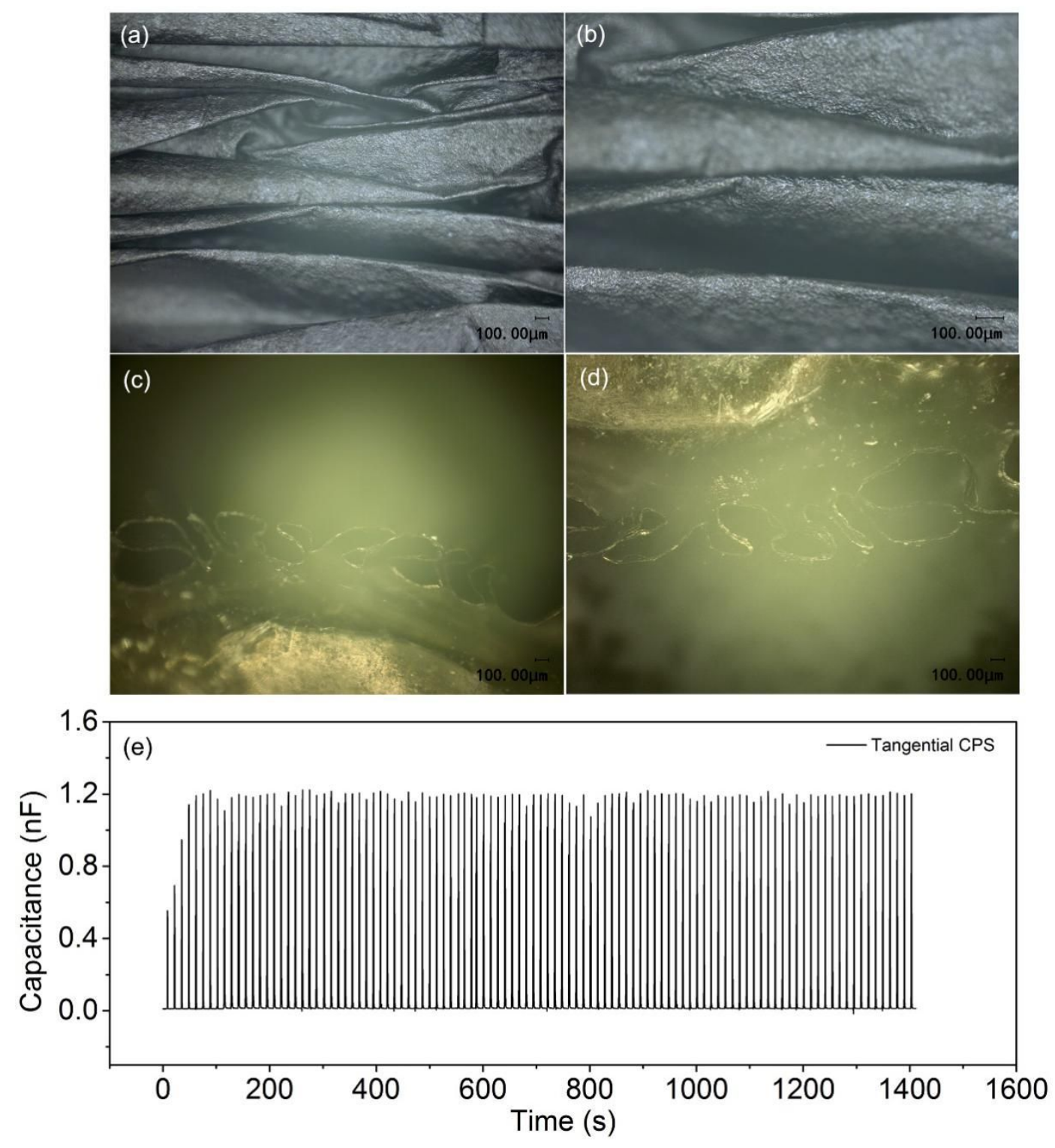

Figure.S12 3D microscope image of $(\mathrm{a}, \mathrm{b})$ rGO-PANI electrode surface and(c, d) cross section after cyclic compression tests. (e)Durability sensing ability of the CPS under $0.2 \mathrm{MPa}$ stress over onehundredcycles. 

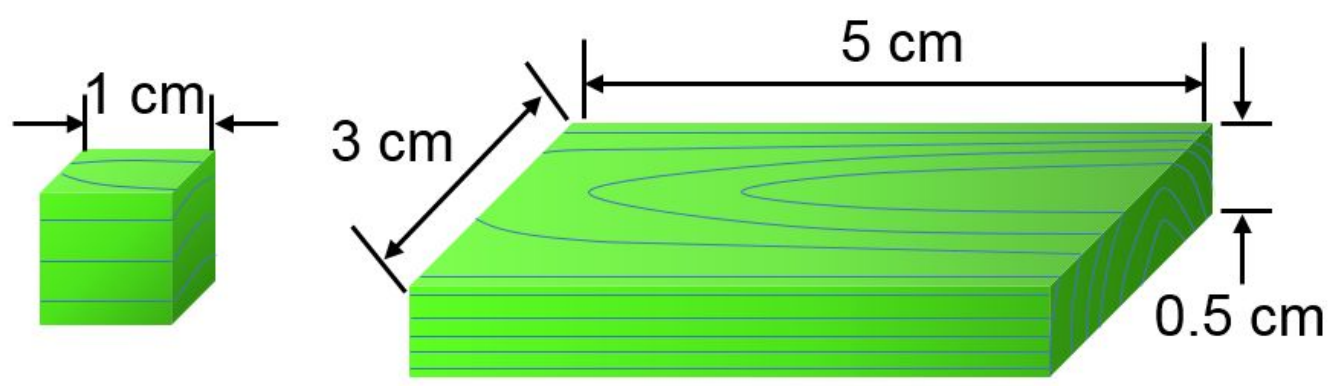

Figure.S13 Schematic diagrams of the wood blocks sawn to sizes of $1 \times 1 \times 1 \mathrm{~cm}$ and $5 \times 3 \times 0.5$ cm (tangential $\times$ cross $\times$ radial $).$

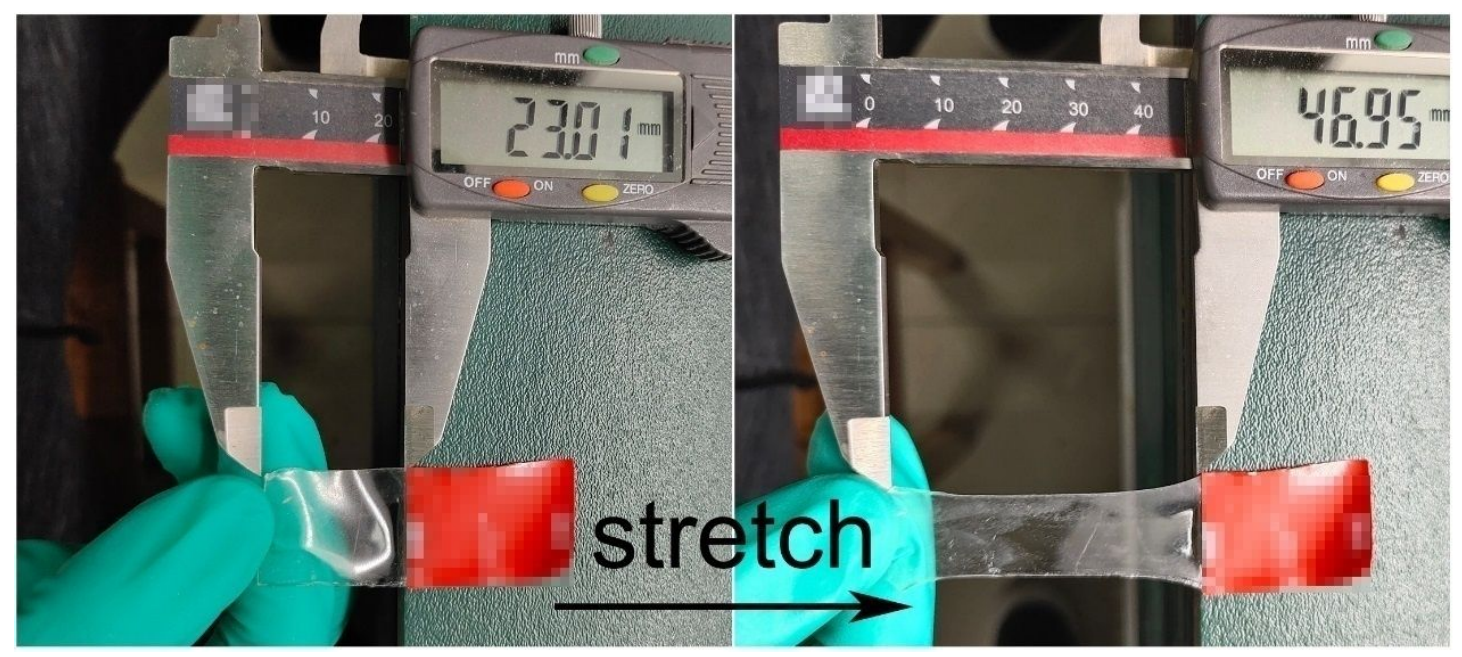

Figure.S14 Stretched VHB substrate (about twice the original length) to make a wrinkled rGO electrode. 